1. Graduate standing in a recognized academic program in either materials science, metallurgy, ceramics, or polymers; physics or chemistry; geology or mineral science; electrical, civil, mechanical, mining or nuclear engineering; or other materials-related field.

2. Participation in a research project dealing with one of the following symposium topics:
a. Laser-Solid Interation
b. Defects in Semiconductor
c. Semiconductor Interfaces
d. Nuclear Waste Management
e. Photo-Thermal Materials
f. Electron Microscopic Imaging
g. Spectroscopic Characterization of
h. Catalyst Supports and Support Effects
i. Hydrogen at Surfaces and Inter- faces
j. Nuclear and Electron Resonance Spectroscopies Applied to Materi- als Science
k. Magnetic and Optical Materials for Information Storage
1. Advances in Cement-Matrix
Composites
m. Synthetic Modulated Materials

3. Outstanding performance in the conduct of this project and promise for future substantial achievement in materials research as judged by the faculty advisor.

4. Significant and timely research results, as judged by the chairman of the appropriate symposium. are:

Application materials required

1. Application form, obtained by writing to:

Secretariat

Materials Research Society

102C Materials Research Laboratory

University Park, PA 16802

2. Abstract of relevant thesis or publication.

3. Letter of support from research supervisor, to be sent to above address.

Deadline for completed applications is September 1, 1980. Results will be announced on October 1.

\section{NOTES ON 1980 MRS MEETING}

A series of interdisciplinary, topical symposia will be held at the annual Materials Research Society Meeting in the Copley Plaza Hotel, Boston, Mass., November 1621,1980 . The symposia will be conducted concurrently with the common goal of discussing new materials development, new characterization methods or new process technology. Each symposium will provide a forum for exchange of ideas at the forefront of research by experts in the field and topics will be treated at a sophisticated level, in an interdisciplinary way, so all possible physical, chemical and engineering insights can be considered.

The symposia for this year's meeting have been conceptually structured in four major areas: electronic materials, energy materials. materials analysis, new and special materials.

Unless specified otherwise in any of the information regarding individual symposia, the deadline for abstracts to be in the hands of the symposium chairperson is July 1 in the format detailed in the program booklet. A program booklet is available by writing to E. Hawk, MRS Executive Secretary.

For information on specific symposia, contact the respective symposia chairpersons. For general program information contact either of the program chairpersons:
K. N. Tu
IBM Research Center
Yorktown Heights, NY 10598
914/945-1602 
C. J. Northrup

Sandia Laboratories

Albuquerque, NM 87175

505/264-5650

For general information concerning the annual meeting contact:

Materials Research Society Secretariat Ernest M. Hawk, Executive Secretary 102C Materials Research Laboratory University Park, PA 16802

814/865-3424

\section{VON HIPPEL AWARD OF THE MATERIALS RESEARCH SOCIETY - NOMINATIONS}

Nominations are invited for the Von Hippel Award of the Materials Research Society. This prize recognizes outstanding practitioners of the multi-disciplinary endeavor of materials research. It is intended to honor pioneers who have shaped our understanding of the mutual enhancement of the various disciplines engaged in the study of materials. The prize was named after its first recipient, Arthur Von Hippel, emeritus professor at the Massachusetts Institute of Technology. Other recipients include Dr. William O. Baker and Professor David Turnbull. The prize consists of $\$ 1000$ and a decorative ruby crystal. Nominations with supporting documentation should be sent before September 1, 1980 to the Chairman of the Awards Committee, Dr. Rudolf J. H. Voorhoeve, c/o Celanese Corp., Summit, N. J. 07901.

\section{ANNUAL MEETING DATE SET}

The 1981 Annual Meeting will be held in Boston, Massachusetts, at the Copley Plaza Hotel from November 15 to November 20. The Lenox Hotel will serve as additional accommodation for attendees.

Program Chairmen for this meeting will be H. J. Leamy (Bell Labs 201 5822628), P. A. Montano (West Virginia
University (304 293-5769), and C. W. White (Oak Ridge, 615 574-6295).

The Chairmen held a meeting at Oak Ridge National Laboratory on June 10 to discuss the 1981 program. Several new developments were proposed and a tentative list of symposia will be given in the next newsletter. The Chairmen welcome any suggestions for new symposia topics. 